\title{
SOCIOLOGICAL REVIEW OF RELIGIOUS IDENTITY AND SOCIAL- MENTAL HEALTH OF SECOND GRADE HIGH SCHOOL STUDENTS OF EDUCATION ORGANIZATION OF DISTRICT 1 IN 2015-2016 EDUCATIONAL YEAR
}

\author{
Ali Radmard \\ M.A. Student, Department Of Sociology, Faculty Of Humanity, Islamic Azad University \\ Zahedan Branch, Zahedan, Iran \\ Asghar Mohajeri \\ Associate Professor, Department Of Sociology, Faculty Of Humanity, Islamic Azad University, \\ Tehran Branch, Tehran, Iran
}

\begin{abstract}
The purpose of the present study is Sociological review of religious identity and social-mental health of second grade high school students of education organization of district 1 in 94-95 educational year. The statistical community includes all the second grade high school students in district 1 of Zahedan which includes 650 persons and statistical sample was based on Cochran formula and through multistage cluster sampling method, 241 persons have been selected and to increase the accuracy of the results and reducing the possibility of incomplete questionnaires and decrease in the number of subjects, by calculating $15 \%$ more, the final number of the sample is 277 persons and 270 complete questionnaires were returned. Researcher-made questionnaires were used for collecting the data of the study and Pearson correlation coefficient was used for hypotheses test. The results of the study show that there is a positive and significant relationship between religious identity and social-mental health of second grade high school students of education organization of district 1 of Zahedan city, there is a positive and significant relationship between religious practices and mental-social health of the second grade high school students of education organization of district 1 of Zahedan city, there's no positive and significant relationship between sex and the willingness to participate in religious rituals in second grade high school students of education organization of district 1 in Zahedan city, there's not a significant and negative relationship between sex and mental-social health of the second grade high school students of education organization of district 1 of Zahedan city. According to the findings of the study, religious identity has a big effect on social and mental health of the students.
\end{abstract}

Keywords: religious identity, social-mental health, students, The city of Zahedan

\section{INTRODUCE THE PROBLEM}

Mental and social health is one of the necessities of the society because favorable performance of a society requires people who are in a good mental condition (Movahed Abtahi, 2008). One of the most important reasons for the importance of reviewing mental health is the high, extreme and lengthy debilitating prevalence of some mental disorders so that according to the reports of scientific communities, over half a billion people around the world suffer from mental disorders and millions of forgotten people tolerate their pain and suffering behind the walls of disappointment not only in silence and isolation but also in embarrassment, privation and death and its consequences can afflict human societies and disturb its developing progress (Sligman and Rooznahan, 2010).

Tendency to love and worship is one of the innate needs of human beings, that is, an independent human being feels the tendency to worship god out of every kind of learning. The reflection of such feeling and tendency is obvious in religious practices and in general the relationship of human and religion, is explainable in the literature of religious identity. According to one of the psychologists, 
the aim of ideology is to create a picture in person's mind to reinforce the personal and collective feeling of identity in him. Obviously, the feeling of commitment and responsibility over values and beliefs of a school are some of the consequences of the evolution of religious identity. Some of the experts consider commitment as the footstone of religious identity (Shamloo, 2011).

Nowadays, different aspects of identity have been considered by many thinkers and theorists. The current condition of global communication, development and growth of different technologies, constant cultural confrontation and ... have turned the problem of identity and its different dimensions including religious and national aspect, to the central subject in social reviews. Youths constitute a high percentage of our society and it is of double importance to our young people because youths in every society, have a determining effect on the future of the society because of enjoying power and energy (Safiri and Ghafoori, 2009).

Youths circulate the wheel of social, economical and political activities of a society, build change in the society and can bring it to the pinnacle of success and glory or can destroy it. Therefore, it is obvious that paying attention to the problems of this group of the society and trying to solve their problems has a special importance. All youths won't succeed in achieving the identity or achieving it completely and that is why these people often face different personal, social problems and negative feedbacks from other people in their present and future lives. In studying human personality, especially its mental aspect, identity has a basic and innate role and a person can connect and relate to his or her past through it and feels consistency and integration in his or her life. In other words, identity is a person's mental picture of himself or herself as a unique and consistent person (Sharifi et.al, 2009).

Recently, psychologists have paid a great deal of attention to the relationship between religion and health and wide scientific studies have been performed in this regard. These studies have studied the effect of religious indicators on mentally ill patients and mental health of the population. They have also reviewed the occurrence rate of depression and behavior disorder and different aspects of mental health of satisfaction of life. In general, the results indicate that religion has been a protective factor against mental illness (Lewin, 2010). Religion has a multi-dimensional structure and every dimension of it effects mental-social health in some way (hackney \& Sanders, 2003). Most people believe that their god will help them whenever they face a problem, the more they grow, their religious and spiritual beliefs increase or it lays a more prominent role in their lives (Rippentrop et al, 2005).

In discussing religious identity, having a common teaching and religion in the society is emphasized. Religious identity is the process of conscious responsiveness of a nation to worldview, ideology, religious teachings and the features of rituals according to their own religious beliefs. Religious identity in a society, on one hand, includes people's adherence to the essence of the religion and religious values and on the other hand is the representative of the collective and public interest of the people of a society to the rituals and religious institutions. It also has a practical aspect which is people's participation and practical tendency to vanities and religious rituals (Molaei, 2007).

Identification and self-knowledge is one of the important issues of adolescence and youth. In these periods, the person is looking to answer the crucial and fateful question of "Who am I?"

The answer to this question can determine the person's position in life and clarify his orientations during his life, whether in personal or social level and give a special flavor to the person's deeds and thoughts by paying attention to the formed identity. Identity and its different aspects (Self-knowledge, knowing others, social, cultural, religious, national \& etc.) is the essential component of life and it is impossible to live appropriately and communicate meaningfully and effectively without having a framework to determine one's identity (Ahadi, 2006).

Religious beliefs have a distinct role in propagating healthy and useful behaviors (Avoiding Tabaco, alcohol, drugs, anti-social behaviors \& etc.) which are useful for mental health. Speaking with people with similar beliefs in either formal or informal social groups will result in obtaining huge emotional 
support. Saying one's prayers individually or with others may create thanksgiving, forgiveness, mercy, love, and provide curative and preventive benefits. Religious beliefs (About God, existence, the life after death, volition, human duties) can be concomitant with activities that foster looking after health. Faith or religious conviction can create positive expectations as we shall see later that hope and optimism can prevent or ameliorate diseases. In general, psychological mediation of religion and mental-social health is believable (Levin, 2009).

Adolescents, as the next generation, play an important role in building the future of the province of Sistan and Baluchistan and Islamic Iran. In spite of increasing development of human society in all fields and the entrance of foreign cultures that oppose to Islam and the presence of adolescents in a stage of life that they are looking to shape themselves and find a pattern in the society, specially adolescents whose thoughts are getting formed, the role of religion as an effective factor in preventing social deviations and increasing Spiritual-mental and social tranquility should be considered more than before, basic plans need to be developed by considering the special conditions of this province and also the lack of attention to religion in the schools of this province and also by considering the role of Education organization as the custodian of the next generation. According to the above, in this study it is emphasized that to what extent can religious identity affect the mental-social health of the students? Therefore, the aim of this research is sociological review of religious identity and mentalsocial health of the second grade students of Education organization of district 1 of Zahedan city.

\section{BACKGROUND}

\section{Internal research}

Fallahi and Abdullah Zade (2014) in a study entitled "The relationship of religious and national identity with mental health among 20-60 years old residents of Gorgan city" concluded that there is not a significant relationship between religious identity and mental health and there is a significant and negative and reversed relationship between national identity (Iran-liking identity and homeland defending identity) and mental health, respectively $(\mathrm{P}>0.01)$ and $(\mathrm{P}>0.5)$ so that if there's a disorder in mental health, national identity will diminish.

Hosseinzade \& Shajaravi (2013) in a study entitled "Reviewing the effect of the amount and type of use of satellite on social, religious and national identity of adolescents" showed that there is a significant relationship between all the independent variables of the research and the dependent variables. Results obtained from regression show that only social and economic base and interest rate about satellite programs and the amount of using satellite have been significant and on aggregate, $21 \%$ of changes related to social, religious and national identity are explained by these two variables. Khaje et.al (2011) in a study entitled "The relationship of religiosity rate with the youths' quality of life; Case study: Youths of Shiraz" showed that reinforcing religious factors, beliefs, individuals' beliefs and religious identity have a distinct effect on ameliorating mental, social and physical health and in general on ameliorating the quality of life.

\section{EXTERNAL RESEARCH}

Lopez et.al (2012) in a study entitled "A longitudinal study on identity and religious participation during adolescence" showed that religious identity among high school students, considering a decrease in religious participation, was stable. Even after controlling tribal conflicts in religious relationships, social and economic background, generational status, youths in Latin America and Asia had higher levels of religious identity and youths of Latin America had a higher religious participation rate. Among youths, changes of religious identity were related to changes of family and tribal identity and represented important links in the development of these social identities during adolescence.

Ahmed and Abdel-Khaled (2011) in a study entitled "The quality of life, mental health and religious identity in Muslim university students" concluded that there is a positive relationship and correlation between the quality of life and religion. 
Lim and Putnam (2010) in a study entitled "Religion, social networks and life satisfaction" showed that religious people are more satisfied because of regular participation in religious rituals and creating social networks in their lives.

\section{Theoretical framework of the study Religious identity}

Religious identity involves a level of religiosity that has a correlation with collective "us" or social religious "us". In fact, religious identity shows the feeling of belonging to religion and religious society and also commitment to religion and religious society. In fact, religious society is the effects and complications caused by religious practices on religious person. In other words, accepting religion as a doctrine and commitment and feeling of belonging to it, will cause important changes and results in the different aspects of devout person's life which are the same religious identity (Chitsaz Qomi, 2010).

Therefore, having religion and common religious teachings, adherence and loyalty to it, belief and tendency to universal religious rituals in the process of shaping one's identity is very effective. Given the fact that one of features of the identity is that it is multi-dimensional and compound, some dimensions have also been considered for religious identity.

\section{Aspects of religious identity}

\section{1- Religiosity and approach toward the soul of the religion}

[Being religious] is a common title that is referred to any person or phenomenon that reflect the values and sings of religion. Reflection of the person's religiosity can be sought and identified in his approach, attitude and overt or covert acts. The religious person on one hand, commits himself to obey religious orders and on the other, hand religious practices turn him into a different person in comparison with others, so we can distinguish him from others through two signs: One, his religious adherence and other the consequences and effects of religiosity in his thought and life and personal and social actions. So, In general religiosity means having religious adherence so that it affects the person's approach and attitude and his actions (Shojaeizand, 2009).

Glark and Stark have cited various religious structures under the names of belief, practice (religious ceremonies or worship), religious experiences, results and consequences and their daily effects. They have summarized the features related to religiosity around the following five dimensions, these five dimensions include:

- Religious belief which includes beliefs that the person is expected to believe in them according to his own religion

- Religious practice which includes rituals and ceremonies that each religion expects its followers to do

- $\quad$ Religious experience that is related to emotions, imaginations and feelings of the followers of a religion about the existence of a god or ultimate reality and transcendent authority

- Intellectual or religious knowledge which includes information or fundamental knowledge about the beliefs of every religion

- $\quad$ Religious consequences which is related to the effects of beliefs, practices, experiences and religious knowledge on daily life and in other words, religious effect and reflection on daily behaviors (Ketabi et.al, 2011).

2- Cultural dimension (Commitment): Salansik believes that commitment includes connecting the person to his personal actions and measures and in general, it means that commitment will become real when a person feels that he is responsible for his behavior and actions. In other words, in this concept, just speaking is not enough and responsibility should follow it as well. So in general we can define commitment as the feeling of loyalty and personal responsibility (Ganji et.al, 2010). Therefore we can define religious commitment as a set of symbolic and pragmatic cognitive elements that form a certain traditional heritage; such as teachings, books, behaviors and rituals, history of ideas and 
thinking methods that originate from social activities of societies, eating habits, dressing, health affairs and so on and so forth that are related to the system of beliefs, art and aesthetic doctrine that have been developed practically and are related to these beliefs, constitute the cultural dimension of identity. In fact, the cultural dimension is Muslims' positive approach toward cultural-religious heritage and their efforts to maintain this heritage (Chitsaz Qomi, 2009).

3- Historical dimension: It means awareness and knowledge about the historical background of a religion and the feeling of belonging and affiliation to it. This dimension includes two components: Historical knowledge which means awareness and knowledge about the most important events and historical characters, and the other is historical fixation which is the presence of positive and negative feelings or emotions toward events, positive and negative events and characters, and causes positive and honorable collision with them or agreeing with activities or effective and positive characters in the history of the country and the feeling of pride or sadness and humiliation (Chitsaz Qomi, 2009). Therefore, this dimension implies individuals' common awareness of their historical past and the feeling of affiliation to it and insisting on maintaining it.

\section{Mental health}

Mental health includes the set of factors that play an active role in preventing the development or progression of worsening cognitive, emotional and behavioral disorders in humans and its main goal is the prevention of diseases and prevention, in its most general meaning, includes: Creating factors that are the supplement of a natural and healthy life along with curing partial behavioral disorders in order to prevent extreme diseases.

Problems related to mental health have existed since the emergence of human beings on earth and no specific person from no social-economic stratification has been immune to it and it threatens almost everyone. Nowadays, the development of industry and technology in human societies has increased power and wealth but it has restrained the opportunity to live with peace and confidence and in fact, «Quality» has been sacrificed for «Quantity» and balance has been destroyed and neurological-mental problems have replaced it (Ganji et.al, 2007).

\section{Social health}

The concept of social health is a concept that has been addressed along with physical and mental aspects and reviews its social aspects by focusing on the person, Health, Quality of life, Social wellBeing, both in individual and societal level are equal with social health (Taqipoor, 2010).

In 1968, the world health organization presented a definition from well-being which is: well-being is person's total welfare in physical, mental and social aspects, not lacking disease or disability. Social health is that aspect of person's welfare that is related to how he communicates with other people (Wilkinson \& marmot, 2009). In fact, a person has social health when he is able to show his activities and social roles in the minimum level and feels attached and connected to society and social norms (Fadaei Mehrbani, 2007).

Keyes (1998) defines social health as person's personal report of the quality of his communication with others. Social health in this concept means person's perception of society as a meaningful, understandable set with potential force to grow and prosper with the feeling that he belongs to the society and feels that he is participating in the development of the society.

Keyes (1998) considers five criterion for social health that develops according to psychological and sociological theory, and they include:

Social integration: Social integration means a person's evaluation by considering the quality of his participation and companionship with his society, the feeling of belongingness can be a key aspect of well-being and therefore integrating with others in environment or society should be the result of a common experience with others, lack of the feeling of social integration, in the highest level, will result in suicide. Healthy people feel that they are a part of the society, so social integration is 
individual's sense of sharing with others who make up his social reality and belong to their own society. Social integration relies on concepts such as Social cohesion (Durkheim), Cultural alienation and social isolation (Seaman) and class consciousness (Marx) (Sam Aram, 2009).

Social contribution: Social contribution includes the person's evaluation of his social value and includes the belief that "Is the person an important part of the society and what value does he add to his own world?"

Social contribution is similar to concepts of efficiency and accountability. Personal efficacy means that we believe that we can show certain behaviors and achieve certain goals. Social accountability includes determining individual necessities to contribute in the society. This dimension of social health refers to whether individuals think that what they do is valuable to the society or no? This approach is in line with the theme that Marx presents that humans are essentially creative (Hatami, 2010).

Social Cohesion: Social cohesion is comparable to the significance of life and includes viewpoints that society is quantifiable and predictable. In psychological point of view, healthy people consider their personal lives significant and coherent. Antonowski believes that the sense of coherence within the individual can be a sign of his well-being, people who have cohesion try to maintain their cohesion when facing unpredictable events. Social cohesion is individual's perception of the quality of his social world and the way of organizing it and its performance (Abdullah Tabar et.al, 2009).

Social prosperity: Social prosperity means "Evaluating the society's potential and its trajectory". Social prosperity includes people's perception of the fact that they will benefit from both social growth and that organizations and people that are present in the society are thriving and this is the sign of optimal development and even though this is not true for all the people in the society, according to Keyes, this concept has a common feature With Mazlo's (1968) "Self-knowledge" and it is not irrelevant to Rieff's emphasis on personal growth. Social prosperity is the reflection of people's proper functioning and its result is that they'll welcome new experiences and persistent growth (Hezarjibi et.al, 2012).

Social acceptance: Social acceptance is the social version of self-acceptance. People who have a positive view about their personality and accept the good and bad aspects of their lives are examples of social and mental health. What is meant by social acceptance is person's perception of the society by considering the characteristics of others. Social acceptance includes accepting proliferation with others, believing in the innate goodness of others and having a positive view about human beings' nature and all of these things will make the individual to feel comfortable with other members of human society. Those who accept others and have come to understand that individuals are generally constructive. As mental health includes self-acceptance, accepting others in the society can lead to social health (Nik varz, 2009).

\section{Sociological theories on religious identity and social-mental health}

Durkheim: According to Durkheim, religion has emerged initially among the early communities when individuals have joined a larger group. At this time, people come to understand a force that seems to be supernatural and the distinction between sacred and non-sacred things is achieved. In fact, in early communities, individuals' social identity is their religious identity that forces them to consider collective benefit. The content of religious symbols and rituals even adjust the material existence of the society (Crippen, 1988).

\section{Parsons}

According to Parsons, personal identity in social system is affected by people's social identity to serve the social system. Parsons believed that culture and religion have a cybernetics identity. Religion could create values, form norms, mediate social roles and provide general guidelines for personality systems, society and behavior through its superior position in the action system (Davis, 1996). 
Eventually, Parsons does not consider religion pushed back and obsolete in modern societies but he believes that because of the generalization of values, sacred concepts will spread in the whole of the society (Gouldner, 1989).

According to this view we can say that Parsons believes that religion enters the personality system and social identity through socialization in the form of social values. In modern societies, personal identity is non-religious because due to functional separations, religious field is separated from economical-social aspects of individuals' lives but will still be present in individuals' social identity because in his view, culture and religion are of great importance in maintaining social order and are capable of leading social actions.

\section{Striker}

Striker is another theorist who has presented some theories about identity. In his view, every role in the society has its own special identity. When people accept different roles in their social lives, their attached identities become inner. Identities are parts of oneself. Self develops some plans according to social structures and their nature and its position in these structures and the roles that it plays in relation to these positions. Identities internalize these created structures. People themselves define symbols, meanings and social positions but these definitions do not fully determine person's behavior because the person can modify the form and content of social interaction depending upon the flexibility of macro structure and identities create a critical connection between the person and this macro structure (Turner, 1998). Therefore it can be said that when people are placed in religious positions, they will have religious identities. Since Striker believes that identities provide a connection between the person and social structure, the importance of people's religious identity can be guessed in their identity hierarchy according to the social structure they live in. The more importance social structure gives to religious roles, the more the number of these roles and social supports that are provided for them and as a result, religious identities will gain higher positions in identity hierarchy and people will tend to accept more religious roles. But if the social structure is anti-religious or nonreligious, identities and social roles will become way more limited and less important (Imanpoor \& Soroush, 2002).

\section{George Herbert Mead}

Herbert Mead is another theorist in the field of identity. Mead believes that identity or self of every person is shaped through organizing others' personal approaches and organized group approaches (Skidmore, 1996). In Mead's social theory, individuals and society are not in contrast with each other like two separate things. They see self as social identity that on one hand originates from mutual relations between person's conversation in his mind, that is, the conversation between "Agent me" and "Objective me" and on the other hand originates from person's conversation with others in the field of social relations (Jenkins, 1996).

In Mead's view, every person forms his identity or "Self" through organizing others' personal approaches in the form of organized social or group approaches. In other words, the picture the person creates in his mind from himself and the feeling he has about himself, is the reflection of the view that other people have about him (Gol Mohammadi, 2007).

\section{Adler's theory:}

Alfred Adler believes that the main issue in human beings is the feeling of humiliation and all the activities of the person are done with the aim of becoming strong and powerful, according to this, each individual's activities are some sort of compensation to eliminate the feeling of humiliation and achieve a more important feeling. Adler defines mental health as: A healthy person defines his lifestyle with total realism so that it does not lead to the feeling of humiliation. He believes that an evolving person fights his problems with the aid of intrinsic forces and environmental facilities and mental activities are caused by individual's goals and a lifestyle is created based on these goals. Adler believes that metal heath means having certain goals in life, having a strong and solid philosophy for 
living, having favorable and stable family and social relationships, being useful for others, having courage and decisiveness in acting to achieve your goals, having control over your feelings and emotions, having an ultimate goal for perfection, accepting problems and trying to solve them.

\section{Durkheim}

Empirically, the concept of social health originates from sociological literature that is related to abnormalities and alienation. But according to health-centered model, the lack of the feeling of abnormality and alienation might not be an indicator for the presence of social health (Keyes, 2004:4). According to Durkheim, social normality is related to the condition of individual's communication with others in the society or in other words to his socialization, any disconnection between the individual and society so that individuals cannot be absorbed to social frameworks provides an anomic and favorable condition for the growth of social deviations. In such a condition, a kind of extreme individualism places individual's wishes against his social life (Tavasoli,1993). In his view, any kind of gap between the individual and society will provide the opportunity for social deviations (Hosseini, 2008).

\section{Goldsmith}

Goldsmith defines social health as «Evaluating individual's meaningful and positive and negative behaviors in communicating with others» and introduces it as one of the most basic indicators of the health of every country that leads to the effectiveness of the individual in the society. Having correct social thoughts and having a positive mentality towards society are the first and most important stages of social health in order to have a better social life. Therefore, due to the social nature of human life and the challenges that this can create, we cannot neglect the social aspects of health along with objective, emotional and psychological aspects (Larson, 1996:285).

\section{Rieff}

The view that was expressed by Rieff believes that the concept of social health includes dimensions of positive performance of mind, these dimensions include:

1. Self-acceptance: Having a positive view about oneself, identifying the different aspects that can be positive or negative, having a positive feeling about one's past.

2. Positive relationship with others: Having a warm, satisfying and confidential relationship with others, paying attention to others' well-being and satisfaction, having a strong feeling of sympathy with other people

3. Self-obedience, being autonomous and independent: The ability to resist against social pressures, the ability to adjust the behavior from inside and evaluate yourself through personal criterion.

4. Overcoming the environment: Having the feeling of domination and superiority over the environment, effective use from provided opportunities, the ability to select or create appropriate contexts for personal needs and values.

5. Having a purpose in life: Having a purpose in life, giving a meaning to life in the past and present, having faith and a belief that gives purpose to life.

6. Personal growth: Having the feeling of constant growth, seeing yourself growing and evolving, being open to new experiences, distinguishing your potentials (Khodayari \& Abedini,2007).

\section{Keyes}

Keyes's work originates from a sociological and psychological principle. According to Keyes, the missing link in the history of health-related studies is the answer to this question that "Is it possible to evaluate individuals' quality of life and personal performance without considering social criteria?"

In response to this question he says that "Good performance in life is something more than physical or mental health and includes social challenges and duties as well". In his view «Social health means how an individual assesses his performance against the society. From social point of view, a healthy person considers society as a meaningful and regular, understandable and potential set for flourishing 
and growth and feels that he belong to the society, and is accepted by the society and has a role in its development » (Keyes, 1998:23).

Table (1) Theoretical table of the study

\begin{tabular}{|c|c|c|c|c|}
\hline $\begin{array}{l}\text { Independent } \\
\text { variable }\end{array}$ & Main hypothesis & Key concepts & Theorist & $\begin{array}{l}\text { The } \\
\text { name } \\
\text { of the } \\
\text { theory }\end{array}$ \\
\hline $\begin{array}{l}\text { Religious } \\
\text { practices }\end{array}$ & $\begin{array}{l}\text { There is a significant } \\
\text { relationship between } \\
\text { religious practices and } \\
\text { mental-social health of } \\
\text { second grade high school } \\
\text { students of Education } \\
\text { organization of district } 1 \text { of } \\
\text { Zahedan }\end{array}$ & $\begin{array}{l}\text { Religion-Social identity- } \\
\text { Religious identity- Religious } \\
\text { rituals- Religious identity }\end{array}$ & Durkheim & \multirow{4}{*}{ 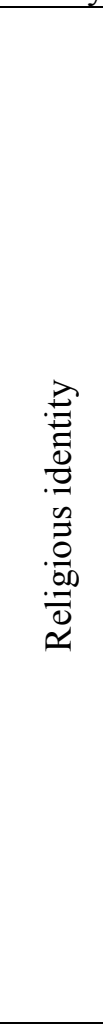 } \\
\hline \multirow{2}{*}{$\begin{array}{l}\text { Religious } \\
\text { beliefs }\end{array}$} & \multirow{2}{*}{$\begin{array}{l}\text { There is a significant } \\
\text { relationship between } \\
\text { religious beliefs and mental- } \\
\text { social health of second } \\
\text { grade high school students } \\
\text { of Education organization of } \\
\text { district } 1 \text { of Zahedan }\end{array}$} & $\begin{array}{l}\text { Personal and social identity - } \\
\text { Religion and moral values - } \\
\text { Religion and culture } \\
\end{array}$ & Parsons & \\
\hline & & $\begin{array}{l}\text { Others' personal views- } \\
\text { Organized view - social } \\
\text { interaction }\end{array}$ & $\begin{array}{c}\text { George } \\
\text { Herbert } \\
\text { Mead }\end{array}$ & \\
\hline $\begin{array}{l}\text { Procedure of } \\
\text { Religious } \\
\text { practies }\end{array}$ & $\begin{array}{l}\text { There is a significant } \\
\text { relationship between } \\
\text { procedure of religious } \\
\text { practices and mental-social } \\
\text { health of second grade high } \\
\text { school students of } \\
\text { Education organization of } \\
\text { district } 1 \text { of Zahedan }\end{array}$ & $\begin{array}{l}\text { Role in the society-ability to } \\
\text { accept identity - Religion }\end{array}$ & Striker & \\
\hline \multirow{4}{*}{ Gender } & \multirow[b]{2}{*}{$\begin{array}{l}\text { There is a significant } \\
\text { relationship between gender } \\
\text { and tendency to participate } \\
\text { in religious rituals in second } \\
\text { grade high school students } \\
\text { of Education organization of } \\
\text { district } 1 \text { of Zahedan }\end{array}$} & $\begin{array}{c}\text { Individual's relationship with } \\
\text { others }\end{array}$ & Durkheim & \multirow{4}{*}{ 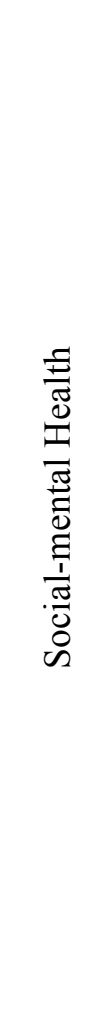 } \\
\hline & & $\begin{array}{c}\text { Evaluating individual's } \\
\text { significant positive and } \\
\text { negative behaviors in } \\
\text { interacting with others - } \\
\text { social networks - } \\
\text { participation in social and } \\
\text { vocational roles - Tendency } \\
\text { to participate in religious } \\
\text { activities } \\
\end{array}$ & Goldsmith & \\
\hline & \multirow{2}{*}{$\begin{array}{l}\text { There is a significant } \\
\text { relationship between social- } \\
\text { mental health and gender in } \\
\text { second grade high school } \\
\text { students of Education } \\
\text { organization of district } 1 \text { of } \\
\text { Zahedan }\end{array}$} & $\begin{array}{c}\text { Self-acceptance - positive } \\
\text { interaction with others - Self } \\
\text { obey- Overcoming the } \\
\text { environment - Having a } \\
\text { purpose in life - Personal } \\
\text { growth }\end{array}$ & Rieff & \\
\hline & & $\begin{array}{l}\text { Having specific goals in life - } \\
\text { having a strong and cogent } \\
\text { philosophy to live - Having } \\
\text { favorable and stable social } \\
\text { and family relationships - } \\
\text { Being useful for others }\end{array}$ & Adler & \\
\hline
\end{tabular}




\section{Conceptual model of the study:}

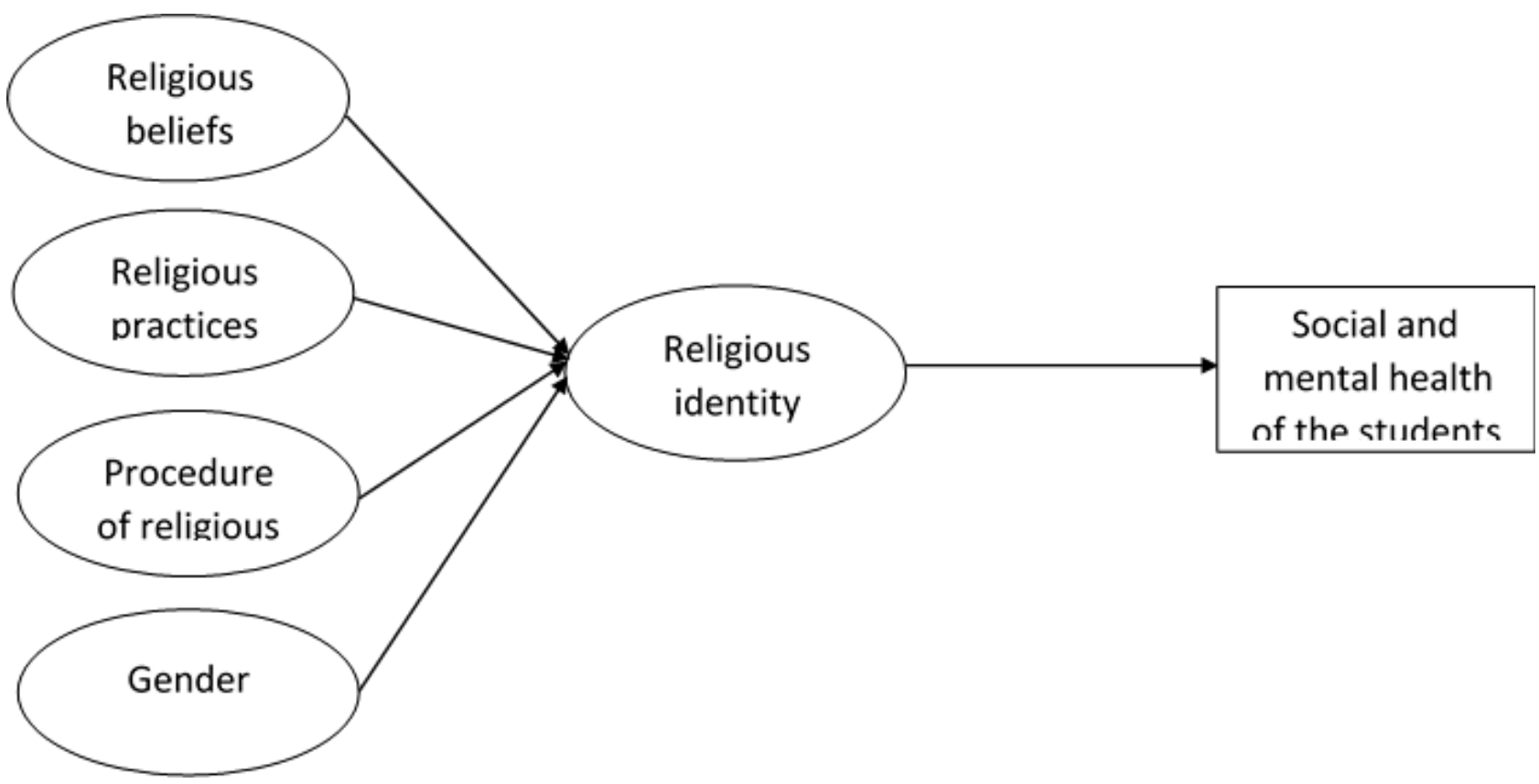

\section{The theories of the study}

\section{The main theory}

There is a significant relationship between religious identity and social-mental health of second grade high school students of Education organization of district 1 of Zahedan city.

\section{Secondary theories}

1. There is a significant relationship between religious beliefs and mental-social health of second grade high school students of Education organization of district 1 of Zahedan city.

2. There is a significant relationship between religious practices and mental-social health of second grade high school students of Education organization of district 1 of Zahedan city.

3. There is a significant relationship between the procedure of religious practices and mental-social health of second grade high school students of Education organization of district 1 of Zahedan city. 4. There is a significant relationship between sex and tendency to participate in religious rituals of second grade high school students of Education organization of district 1 of Zahedan city.

5. There is a significant relationship between sex and mental-social health of second grade high school students of Education organization of district 1 of Zahedan city.

\section{Research method:}

The research method is descriptive and exploratory. The statistical population of the present study includes all the second grade boy and girl high school students of Education organization of district 1 of Zahedan city who are studying in the educational year of 94-95 in state schools and their total number is 650 persons. Considering the fact that the sample size included 382 persons based on Cochran formula, researcher calculated $15 \%$ more in order to increase the stability of research tools, 277 persons were selected as the final sample size and after collecting information, some of the incomplete questionnaires were excluded and data analysis was performed based on 270 questionnaires.

$$
\begin{gathered}
n=\frac{N z^{2} \alpha / 2 p(1-p)}{(N-1) d^{2}+z^{2} \alpha / 2 p(1-p)} \\
n=\frac{(650)(1 / 96)^{2}(0 / 5)(1-0 / 5)}{(650-1)(0 / 05)^{2}+(1 / 96)^{2}(0 / 5)(1-0 / 5)}=241
\end{gathered}
$$

\section{Sampling method:}


In general, the sampling method in this section is Probability sampling (that is the equal probability of the presence of all members of the statistical population in sampling process) and it is of multi-stage cluster sampling type.

Among 4 boys high schools and 9 girls high schools of district 1 of Zahedan city, 3 girls high schools and 3 boys high schools were selected randomly, and from within these schools (clusters) and among first, second and third and pre-university grades, the second grade high school students were selected randomly.

\section{Validity of research tools}

After designing the questions of related varieties, the questionnaires were given to an expert (Supervisor). The comments of these individuals regarding the evaluation of the questions of each variety, eventually led to the evaluation of appropriate questions for each variety. In order to evaluate the validity of the questions, in addition to relying upon the theoretical foundations of the research, experts in Sociology were also used. In the present study in addition to the library method to modify the matters related to theoretical foundations and research backgrounds and referring to scientific sources, researcher made questionnaire was used to measure and evaluate the sociological review of religious identity and mental-social health of the students. The most important statistical methods applied in this study were Cronbach's alpha test which has been used to calculate the reliability coefficient of measurement tools and the result was $0 / 80$, also Pearson correlation coefficient was used to confirm or reject the hypotheses.

\section{Descriptive findings of the study}

Table (2) Distribution of respondents based on personal characteristics

\begin{tabular}{cccc}
\hline Percentage & Frequency & Articles & Variable \\
\hline $50 / 7$ & 137 & Male & Sex \\
$49 / 3$ & 133 & Female & \\
& & 16 years old & Age \\
$61 / 1$ & 165 & 17 years old & \\
$18 / 9$ & 51 & 18 years old & \\
20 & 54 & Human sciences & \\
$32 / 6$ & 88 & Natural sciences & Major \\
37 & 100 & Mathematics and & \\
$30 / 4$ & 82 & physics &
\end{tabular}

The table showed that 137 (50/7 percent) of the respondents were male and 133 persons (49/3 percent) were woman and the majority of the respondents were men; 165 persons $(61 / 1$ percent) were 16 years old, 51 persons (18/9 percent) were 17 years old and 54 persons ( 20 percent) were 18 years old and the majority of respondents were 16 years old and the majority were men; 90 persons (20.9 percent) were single and 340 persons (79.1 percent) were married and majority of the respondents were married persons, 88 persons (32/6 percent) were the students of Human sciences, 100 persons (37 percent) were the students of natural sciences and 82 persons (30/4 percent) were the students of mathematics and physics and the majority of respondents were the students of natural sciences.

\section{Data analysis}

The main criteria for a hypothesis to be valuable is its testing ability and hypothesis testing is evaluating the accuracy of the claim presented by the researcher. Although a hypothesis can never be proved definitely, but it can be confirmed or rejected. So, one of the most important criteria of statistical decision making, is judging the research hypothesis (Mahdavi, 2004).

Table (3) Obtained results from Pearson correlation coefficient

\begin{tabular}{cccccccc}
\hline $\begin{array}{c}\text { Type of } \\
\text { relationship }\end{array}$ & $\begin{array}{c}\text { Correlation } \\
\text { intensity }\end{array}$ & $\begin{array}{c}\text { Existence of } \\
\text { a } \\
\text { relationship }\end{array}$ & Sig & $\begin{array}{c}\text { Correlation } \\
\text { coefficient }\end{array}$ & N & $\begin{array}{c}\text { The name } \\
\text { of the } \\
\text { variable }\end{array}$ & Variable \\
\hline $\begin{array}{c}\text { Direct and } \\
\text { positive }\end{array}$ & High & Yes & $0 / 000$ & $0 / 570$ & 270 & $\begin{array}{c}\text { Religious } \\
\text { identity }\end{array}$ & $\begin{array}{c}\text { Social-mental } \\
\text { health }\end{array}$
\end{tabular}


The Turkish Online Journal of Design, Art and Communication - TOJDAC July 2016 Special Edition

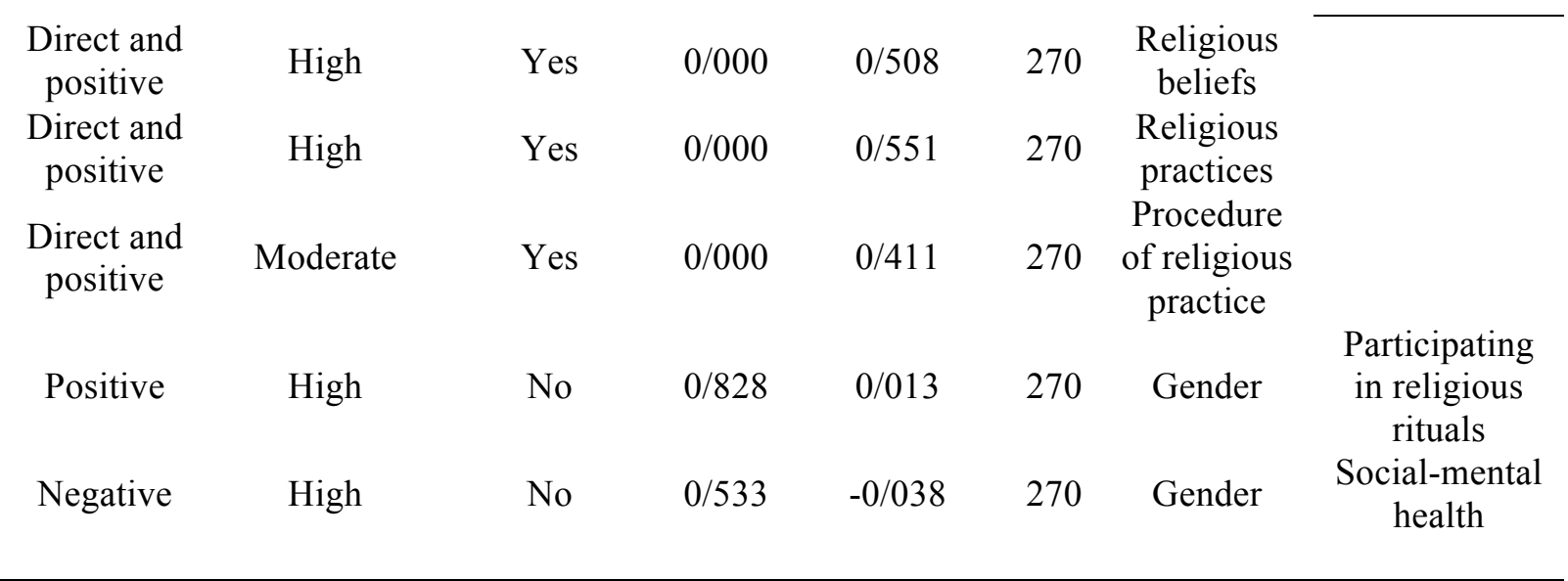

\section{CONCLUSION}

This study was performed with the aim of sociological review of religious identity and mental-social health of second grade high school students of Education organization of district 1 of Zahedan city in the educational year of 94-95; the obtained results from data analysis show that there is a significant and positive $(\mathrm{P}<\% 5)$ relationship between religious identity and mental-social health of second grade high school students of Education organization of district 1 of Zahedan city, also the highest average belonged to the procedure of religious practice with the average of 3/36 percent and the lowest average belonged to religious practices with the average of $2 / 88$ percent. Therefore, according to the findings of the study, it can be inferred that religious identity has a huge effect on mental and social health of the students and there was no relationship between gender and religious identity and mentalsocial health; therefore according to the effect of religious identity on the students, we should pay attention to religion as the basin foundation in human life specially in schools more than before and familiarize students with the blessings of religion and its teachings and pay more attention to the practical aspect of religion.

\section{Practical recommendations}

According to the findings of the research, some recommendations are presented as follows:

- $\quad$ Pay more attention to religion in human life through delicate and accurate planning and Education organization should perform better in familiarizing youths and adolescents with religion.

- Considering the fact that religious identity has a lower level among high schools students, it is better for organizations like the Ministry of culture, The ministry of education and etc. to design various and attractive plans for youths and their families in relation to religious and national issues and provide the opportunity for families and youths to participate in these programs.

- Design practical courses about religious issues in universities, schools and in general educational institutions and encourage youths to have active participation in class activities.

- Implementing cultural programs in schools can be a solution to attract youths and their families to religious issues and educate them.

\section{REFERENCES}

1. Abdullah Tabar Darzi, Hadi, (2009) Reviewing the relationship between social health and social demographic variables of the students of the University of Welfare and Rehabilitation. M.A. Thesis of the University of Welfare and Rehabilitation.

2. Ahadi, Hassan and jamhari, Farhad (2006) Developmental psychology of adolescence and adulthood (Youth, middle age, old age). Tehran: Pardis.

3. Ahmed, M. \& A. Abdel-Khalek (2011). "Quality of Life, Subjective Well- Being, and Religiosity In Muslimcollege Students", Quality of Life Research, vol. 19, N. 8: 1133-1143

4. Ashly and Orenstein (1995), Sociological theory,Classical Statements, Mussuchusett, Allyn and Baccon 
5. Chitsaz Qomi, Mohammad Javad (2009), Generational gap in Iran: Fantasy or reality, Tehran, Jahad Daneshgahi publicatios.

6. Davis, Winston (1996), Sociology of religion, Religious studies, Translated by Baha'aldin Khoramshahi, Research Center for Humanities and Cultural Studies, Tehran

7. Fadaei Mehrabani, Mahdi, (2007), Urbanization, media and social health, Sanjesh and Pazhohesh publication, $149^{\text {th }}$ edition.

8. Fallahi, Mina \& Hassan Abdullahzade (2014) The relationship of religious and national identity with mental health among 20-60 years old individuals of Gorgan city, The first Global Conference on Sustainable Development in Psychology, social and cultural studies.

9. Ganji, Hamze, (2007). Mental health, Tehran, Arasbaran

10. Golmohammadi, Ahmad, (2007), Globalization, culture, identity, Tehran, Nei publications, $2^{\text {nd }}$ edition

11. Gouldner, Alvin (1989), Crisis in the sociology of the West, Translated by Faride Momtaz, Joint stock company publications, Tehran

12. Hackney , C . Sanders ,G. (2003) ." Religiosity and Mental Health: A Meta-Analysis of Recent Studies " . Journal for the Scientific Study of Religion 42:1 . 43-55.

13. Hatami, Parisa (2010) Reviewing the effective factors on students' social health by focusing on social network, M.A. Thesis, Faculty of Social Sciences of Allameh Tabatabai University

14. Hezarjibi, Jafar, Safari Shali, Reza (2012). Anatomy of social welfare. $1^{\text {st }}$ edition, Culture \& society publications, Tehran.

15. Hossein Zade, Ali Hossein; Shajaravi, Mohammad (2013) Reviewing the effect the amount of use and type of use of satellite on adolescents' social, religious and national identity, Quarterly of police knowledge of the province of Khuzestan, No. 5, Pages 13-32.

16. Imanpoor, Mohammad taqi \& Soroush, Maryam (2002), "Reviewing and assessing the effective factors on religious identity in youths of Shiraz city", Scientific journal of literature and humanities faculty of Isfahan university, Number $30 \& 31$

17. Jeff Levin (2010)."Religion and Mental Health:Theory and Research". International Journal of Applied Psychoanalytic Studies .Int. J. Appl. Psychoanal. Studies . Published online in Wiley InterScience . DOI:10.1002/aps.240.

18. Jenkins, Richard. (2002). Social identity, Translated by Tooraj Yarahmadi, Tehran, Shirazeh publications

19. Ketabi, Mohammad et.al (2011). "Religion, social capital and cutural-social development", Journal of Isfahan University, $2^{\text {nd }}$ issue: $169-192$.

20. Keyes , C . M ( 1998 ). Social well-being . social psychology Quarterly . 2 . $121-140$

21. Keyes , C . M ( 1998 ). Social well-being . social psychology Quarterly . 2 . $121-140$

22. Keyes, C. L. M. (2004). Complete mental health: an agenda for the 21 century. Washington.

23. Khaje Noori, Bizhan, Zahra Riahi and Ibrahim Mosavat (2011), The relationship of religiosity with youths' quality of life, Case study: Youths of Shiraz, Cultural research, $12^{\text {th }}$ year, No. $159-127.14$

24. Lim, C., Putnam, R. D. (2010). " Religion, Social Networks, and Life Satisfaction", American Sociological Review, 75 (6): 914-933.

25. Lopez, A. B., Huynh, W. V., Fuligni, A. J., (2012)A Longitudinal Study of Religious Identity and Participation During Adolescence, Volume 82, Number 4, Pages 1297-1309.

26. Movahed Abtahi, Hassan (2008) Necessities of mental health. Tehran: Roshd

27. Nik Varz, Tayebe (2009) Reviewing the relationship of social capital with social health of the students of Shahid Bahonar University of Kerman, Accessible in www.hu.hamandishi.net

28. Rippentrop, A.E., Altmaier, E.M., Chen, J.J., Found, E.M., \& Keffala, V.J. (2005). The relationship between religion/spirituality and physical health, mental health, and pain in a chronic pain population. Pain, 116, 311-321

29. Safiri, Khadije \& Ghafoori, Masume, (2009) "Reviewing religious and national identity of the youths of Tehran city with emphasis on the effect of family", Journal of youth, culture and society, $2^{\text {nd }}$ issue, Spring and summer, 27-1 
30. Sam Ara, Ezat Allah (2009) Reviewing the lationship of social health with social security with emphasis on community-based policing approach, Journal of social regulation, $1^{\text {st }}$ year, No. 1.

31. Seligman, Martin. P; Rooznahan, David. L (2009). Psychology of abnormalities. Tehran: Salavan.

32. Shamloo, Saeed (2011). Schools and theories on personality psychology, Tehran, Roshd.

33. Sharifi, Tayebe, Shekar Shekan, Hassan, Ahadi, Hassan, Mazaheri, Mohammad Mahdi (2009) Reviewing the relationship between religious and national identity with students' mental health, (Social psychology) New findings in psychology, $4^{\text {th }}$ period, $11^{\text {th }}$ issue, pages $125-142$.

34. Shojaei Zand, Alireza (2009), "The religion of society", Tehran, Markaz pubications

35. Skidmore (1996): Theoretical thinking in sociology, a group of translators, Tehran, Safir pblications

36. Taqi poor, Malihe. (2010). Reviewing social support on social health of household women in Tehran city. M.A. Thesis, Azad university of Roodhan.

37. Tavasoli, Gholamabbas. (1997). Sociological theories, Tehran, Semat publications

38. Tavasoli, Gholamabbas. (2003). Sociological theories, Nei publications, Tehran 